\title{
CÍRCULO DE LEITURA LITERÁRIA: UMA POSSIBILIDADE DE CONSTRUÇÃO DE DISPONIBILIDADE AO ENCONTRO COM UM SENTIDO LITERÁRIO
}

\author{
João Carlos BIELLA \\ (Universidade Federal de Uberlândia) \\ jocabiella@bol.com.br \\ Sandra BORGES \\ (Universidade Federal de Uberlândia) \\ borgessandra1@gmail.com
}

\begin{abstract}
Resumo: O presente artigo é produto da experiência com disciplinas de Literatura, no Mestrado Profissional de Letras, na Universidade Federal de Uberlândia, particularmente com as disciplinas Leitura do texto literário e Literatura infantil e juvenil. Surgiu da urgência de demonstrações de metodologias e estratégias para realização de atividades que valorizem o letramento literário, na perspectiva da construção de um sentido literário numa comunidade leitora situada. A estratégia escolhida para a atividade foi o círculo literário. Assim, este artigo discute a eficácia dos círculos de leitura literária, tendo como parâmetro reflexivo inicial algumas proposições de Michèle Petit (2009). Apresenta também o modelo de círculo escolar de leitura literária proposto por Rildo Cosson (2014), numa sistematização feita a partir da observação de diversas realizações de círculos de leitura e de críticas feitas a seus procedimentos, demonstrando sua aplicação em uma turma de alunos do $5^{\circ}$ ano do Ensino Fundamental de uma escola pública municipal de Uberlândia-MG. Na atividade, foram escolhidas obras diversas e variadas para a realização do projeto, entre elas história em quadrinhos, romances e novelas adaptados para o leitor infantil, e poemas. Todas as etapas foram registradas, privilegiando-se as atividades de reconhecimento dos conhecimentos prévios e de escrita de diário de leitura.
\end{abstract}

Palavras-chave: Círculo de leitura literária. Literatura infantil. Ensino de literatura na escola.

\section{LITERATURE CIRCLES: A POSSIBILITY OF AVAILABILITY CONSTRUCTION TO MEET A LITERARY MEANING}

Abstract: This article is the result of some experiences developed in literature courses at the Mestrado Profissional de Letras (Professional Masters in Languages), at Universidade Federal de Uberlândia, particularly, from the courses Leitura do texto literário (Reading of literary texts) and Literatura infantil e juvenil (children's and young people's literature). It emerged from the urgency for demonstration of methodologies and strategies aiming at the execution of activities that valorize literary literacy, focusing on the construction of literary meaning in a specific reading community. The strategies chosen for the activity was the one known as literature circle. Therefore, this article discusses the efficiency of the 
literature circles, taking as an initial reflexive parameter some propositions put forth by Michèle Petit (2009). It also shows a model of a school literature circle suggested by Rildo Cosson (2014), along with a systemization done from the observation of several literature circle reunions and from some criticism made concerning these procedures. Then, the text shows the application of the systemization in a fifth grade class of students from the elementary school of a public school in Uberlândia-MG. Diverse and varied literary works were privileged during the execution of the project, such as comic books, poems, novels and stories adapted to the young reader. All the steps of the project were registered, focusing on the activities of prior knowledge acknowledgement and the production of a reading diary.

Keywords: Literature circles. Children's literature. Literature teaching at school.

\section{Palavras iniciais}

Para que a escola possa promover o letramento literário, é preciso que tenha ao seu dispor formas de mediar o ensino que valorizem o artefato literário e a interação entre o texto e o leitor. É esse diálogo que possibilita que o leitor se aproprie da literatura e que se sirva dela quando quiser, nas palavras de Michèle Petit (2009).

Uma comunidade escolar de leitores reunida em círculo de leitura é uma dessas formas eficazes de mediar o ensino de literatura visando ao letramento literário, na visão de Petit (2009) e também de Rildo Cosson (2014). Para Petit, o compartilhamento de leituras na comunidade escolar proporciona ao leitor, entre outros benefícios, melhores capacidades de se expressar, de produzir experiências estéticas, além de favorecer a apropriação da cultura escrita.

Cosson (2014, p. 139) diz que os círculos de leitura possuem caráter formativo, visto que "proporcionam uma aprendizagem coletiva e colaborativa ao ampliar o horizonte interpretativo da leitura individual por meio do compartilhamento das leituras e do diálogo em torno da obra selecionada [...]". Outrossim, da oportunidade de os leitores literários em formação conviverem e se apropriarem de estratégias de leituras.

É pelo reconhecimento da contribuição que os círculos de leituras literárias podem oferecer para a construção de disponibilidade ao texto, desencadeando o desejo de ler literatura, que os mesmos têm sido adotados nas escolas. 
Acreditamos, portanto, que é um dos meios de a escola mediar, de forma produtiva, o diálogo entre o texto e o leitor.

\section{1 - $O$ círculo de leitura}

Segundo Michèle Petit (2009), os círculos de leitura ${ }^{1}$ ou clubes de leituras ou ainda cafés literários são fenômenos antigos, muito presentes no mundo anglo-saxônico no século XIX. No entanto, foi a partir dos anos de 1990 que eles se multiplicaram em vários países, inclusive no Brasil.

O que configura um círculo de leitura? Configura-se pela reunião de pessoas em torno de algum texto, seja ele verbal, não verbal ou multimodal, com a finalidade de se efetuar uma leitura compartilhada do mesmo. As pessoas podem se reunir, ainda de acordo com a pesquisadora citada, em diferentes espaços $^{2}$, privados ou públicos, e o compartilhamento de leituras, em se tratando da literatura, é potencialmente favorável à produção "de experiências estéticas transformadoras (além de favorecer a apropriação da cultura escrita)" (PETIT, 2009 , p. 142). Isso se deve ao fato, segundo a autora, de que as atividades dos círculos giram em torno de trocas de informações e de comentários sobre o tema do texto ou obra lida, as ideias, a recepção, a relação do que foi lido com diferentes aspectos da vida, mas também sobre a técnica de escrita utilizada pelo autor.

Michèle Petit (2009, p. 160-161), ao ressaltar a importância dos círculos de leitura, diz que " [...] trata-se de revalorizar as palavras e as trocas de linguagem, e de estimular a oralidade nos debates, relatos de histórias, na análise de dados, assim como na escrita (ler e escrever concebidos como momentos inseparáveis de um mesmo processo [...]", o que, para ela, contribui para formação de indivíduos políticos, visto que a leitura instaura a reflexão.

Nesse sentido, os círculos de leitura são atividades que trazem no seu íntimo a dimensão política. Sendo assim, para Petit (2009), as leituras de obras literárias devem ser privilegiadas, pois, devido ao fato de serem polissêmicas, se tornam propícias para que o indivíduo olhe o mundo de forma inaugural, que encontre diferenças para se questionar, ou semelhanças, que são, para ela, os ecos de suas próprias experiências.

\footnotetext{
${ }^{1}$ Adotaremos neste trabalho a denominação círculos de leitura.

${ }^{2}$ Podemos incluir também o espaço cibernético.
} 
Quanto ao círculo de leitura promovido no espaço escolar, Petit (2009, p. 71) coloca que é uma forma de "[...] facilitar a apropriação da cultura escrita por caminhos diferentes dos habitualmente seguidos em sala de aula, apoiar a construção de um espírito crítico e de uma cidadania viva, compartilhar experiências estéticas etc."

Em 2014, Rildo Cosson traçou de forma detalhada no livro Círculos de leitura e letramento literário as possibilidades de organização de círculos de leitura literária dentro da escola. ${ }^{3}$

\section{2 O círculo escolar de leitura}

Existem vários modelos de círculos escolares de leitura, mas, em relação ao literário, Cosson (2014) utiliza em seu livro o modelo proposto por Harvey Daniels (2002, apud COSSON, 2014). Este modelo de círculo de leitura literária, segundo Cosson, começa com a seleção de livros pelo professor, segundo os interesses dos alunos. A seleção pode ser guiada por temas, autores ou gêneros. Portanto, os alunos devem escolher os livros de suas preferências dentre uma seleção feita pelo professor. A partir das escolhas, os grupos de leitura são montados, preferencialmente com quatro a seis componentes. Depois, 0 cronograma de leitura e de discussão de leitura nos grupos é estabelecido.

O passo seguinte é a efetivação da leitura, que deve acontecer em casa, juntamente com o registro escrito da leitura nas fichas de função elaboradas pelo professor e também nos diários de leitura.

\section{2 - Aplicação de um círculo escolar de leitura literária}

Para melhor compreensão do funcionamento do círculo de leitura literária proposto por Cosson (2014), detalharemos nesse item a sua aplicação em uma turma de alunos do $5^{\circ}$ ano do Ensino Fundamental de uma escola pública municipal situada em Uberlândia -MG.

\footnotetext{
${ }^{3} \mathrm{O}$ livro abarca também os círculos fora da escola, que não nos interessam aqui.
} 


\subsection{Justificativa da seleção das obras}

Escolhemos para esse círculo de leitura literária cinco obras, sendo que quatro são HQs e uma é um poema. São elas: Frankenstein, adaptada por Fiona MacDonald (Editora Nacional), Drácula, adaptada por Fiona MacDonald (Editora Nacional), O médico e o monstro, adaptada por Seán Michael Wilson (Editora Nacional) e O Fantasma de Canterville, adaptada por Fiona MacDonald (Editora Nacional) e É isso ali: poemas-adulto-infanto-juvenis, de José Paulo Paes (editora Salamandra). Nesta última obra nos ateremos somente ao poema "Quatro historinhas de horror".

Ao escolhermos as narrativas quadrinísticas e a narrativa poética para a composição do círculo, levamos em consideração que ambas ampliam os modos de ler. A narrativa quadrinística exige a participação dinâmica dos sentidos no ato da leitura, pois a informação se dá pela complementaridade de códigos verbais e não verbais. Já a poesia "tende a chamar atenção da criança para as surpresas que podem estar escondidas na língua que ela fala todos os dias sem se dar conta" (PAES, 1996, p.24). Além da ampliação dos modos de ler, acreditamos ainda que essas particularidades em relação às maneiras das leituras serem efetuadas tornam os contatos com as obras e com o texto poético mais atraentes para o aluno leitor infantil, que é o nosso leitor-alvo.

As quatro primeiras obras escolhidas fazem parte da literatura de horror, um gênero literário que contém elementos do insólito, muitas vezes associados a componentes típicos, por exemplo, da ficção científica, do folclore, da cultura tradicional, da religião ou mesmo de supostos poderes latentes no ser humano. Assim, o insólito, para nós, foi o elemento que os escritores das obras escolhidas para esse círculo de leitura literária ${ }^{4}$ usaram para desestabilizar o real e aproximálo da fantasia, o que, de acordo com Roas (2014), faz com que o leitor interrogue a realidade e perca a segurança ora proporcionada por ela. Essas obras tratam do sobrenatural, ou seja, "aquilo que transgride as leis que organizam o mundo real, aquilo que não é explicável, que não existe, de acordo com as mesmas leis" (ROAS, 2014, p. 31).

\footnotetext{
${ }^{4}$ Mary Shelley é autora de Frankenstein, Bram Stoker é o autor de Drácula, Robert Louis Stevenson é autor de $O$ médico e o monstro e Oscar Wilde é o autor de O fantasma de Canterville.
} 
Já o poema "Quatro historinhas de horror", de José Paulo Paes, utiliza o humor combinado ao sobrenatural em poemas (supostamente) de horror. De acordo com Roas (2014), ao utilizar o humor, o poeta oferece um tratamento das personagens insólitas totalmente descrente, o que desvirtua o possível efeito fantástico do horror e, consequentemente, o medo que seria gerado pela leitura é destruído. Assim, as personagens insólitas são transformadas em personagens familiares dos leitores.

Nesse sentido, acreditamos que a leitura das obras escolhidas, cujas temáticas giram em torno do sobrenatural, estabelece laços com a vivência e a necessidade lúdica dos nossos leitores-alvo. As HQs os interrogam e os fazem perder a segurança diante do mundo real, instaurando um clima de medo que os instiga a adentrar na narrativa. Já o poema, cuja presença do sobrenatural é apenas um pretexto, estabelece o riso, levando os leitores a compartilharem do destino inusitado das personagens insólitas.

\subsection{Passos para a efetivação do círculo de leitura proposto}

A fim de tornar mais detalhado o funcionamento do círculo de leitura literária que adotamos aqui, discorreremos todos os seus passos.

\subsubsection{Explicação aos alunos leitores a respeito da dinâmica de leitura}

Esclarecemos aos alunos leitores que seriam divididos, temporariamente, em quatro grupos de oito ${ }^{5}$ integrantes e que os grupos se reuniriam para efetuar a leitura de uma obra selecionada para uma dinâmica de leitura chamada círculo. Ressaltamos que deveriam fazer um registro do que foi lido, através do preenchimento de uma ficha de leitura elaborada pela professora, tendo como parâmetro a função que cada um assumiria no grupo (conector, questionador, iluminador, ilustrador, dicionarista, sintetizador, pesquisador, cenógrafo e perfilador). Esclareceremos que a discussão da obra ou texto seria feita através dos dados que fossem anotados e que, após a discussão, deveriam fazer registros pessoais no diário de leitura.

\footnotetext{
${ }^{5}$ Cosson (2014) orienta que os grupos precisam ser pequenos (quatro a cinco alunos). No entanto, com leitores em formação achamos mais viável fazer menos grupos com mais alunos.
} 


\subsubsection{A escolha das obras ${ }^{6}$}

Como todas as obras selecionadas abordam temas que partiram da vivência lúdica dos alunos leitores, visto que tratam do sobrenatural através de ângulos diferentes, fizemos a distribuição delas através de uma brincadeira.

Porém, antes, para que os alunos leitores falassem sobre suas leituras, perguntamos sobre o que já conheciam de literatura que aborda o sobrenatural. Anotamos no quadro as colocações feitas e informamos que o gênero fantástico horror seria enfocado no círculo de leitura, bem como um poema que brinca com a temática do referido gênero. Falamos também que as obras em HQs selecionadas são representativas do gênero em questão e que o texto poético, que foi desmembrado em quatro partes, enfoca os seres do horror tratados nelas, porém de forma humorística.

A atividade efetuada, além de distribuir as obras entre os alunos, serviu também para levantar seus conhecimentos prévios a respeito das personagens centrais das histórias selecionadas. $O$ procedimento organizou-se nas etapas descritas a seguir. Primeiramente, em cada canto da sala colocamos uma caixa preta fechada, cada qual numerada de $1 \mathrm{a} 4$. Depois cada aluno retirou de dentro de um saco preto um papel numerado de 1 a 4 . Assim, todos os alunos que retiraram o papel com o numeral 1 abriram a caixa com o numeral 1 e verificaram o que havia dentro e assim sucessivamente. Na caixa 1 havia a história em quadrinhos Frank em "Sombras na parede", de Maurício de Sousa, na caixa 2 havia Zé Vampir em "O vampiro da sopinha de legumes", na caixa 3 Lobi em "Uivo ulutante" e na caixa 4, Penadinho em "Bons sonhos", também de Maurício de Sousa ${ }^{7}$. Assim, as histórias em quadrinhos focaram as personagens que foram trabalhadas no círculo de leitura: Frankenstein, vampiro, monstro (representado pelo monstro folclórico Lobisomem) e fantasma. Após a leitura das histórias em quadrinhos na sala de aula, os conhecimentos prévios sobre as personagens referenciadas foram levantados.

\footnotetext{
${ }^{6}$ Embora Cosson (2014) ressalte que as obras deverão ser escolhidas pelos próprios alunos, não seguimos essa lógica devido ao fato desse ser o primeiro círculo desses alunos e também por eles serem leitores em formação, ou seja, infantis.

7 Turma do Penadinho, criada em 1963, parodia o gênero horror. São monstros, fantasmas e seres insólitos tentando se divertir no cemitério. Frank parodia Frankenstein, Zè Vampir parodia um vampiro, Lobi parodia um lobisomem e Penadinho parodia um fantasma.
} 
Em seguida, os alunos foram informados de que o grupo 1 leria Frankenstein em HQ, o grupo 2 leria Drácula em HQ, o grupo 3 leria $O$ médico e monstro em $\mathrm{HQ}$ e o grupo 4 leria $O$ fantasma de Canterville em $\mathrm{HQ}$; e as respectivas obras originais Ihes foram apresentadas. Informamos também que 0 círculo de leitura seria encerrado com a leitura de historinhas poéticas de horror de José Paulo Paes, a respeito de cada personagem.

\subsubsection{Modelagem}

A modelagem consiste, segundo Cosson (2014), em desmonstrar como funciona o círculo de leitura e os procedimentos que os alunos leitores deverão obedecer em todas as suas fases. Assim, antes de começarmos a leitura das obras selecionadas para o círculo propriamente dito, ensinamos como se faz o registro da leitura, utilizando os textos de Maurício de Souza que estavam nas caixas numeradas, bem como ressaltando as habilidades sociais necessárias nessa atividade (manter a conversa no grupo sobre a obra ou texto, ouvir o colega do grupo, responder quando perguntado, falar olhando para o colega, dar vez à fala do colega, não dominar a discussão etc.).

Como utilizamos para o registro dos tópicos que foram discutidos sobre a leitura das obras e dos textos as fichas de funções que Cosson (2014) buscou em Daniels (2002), conforme citado no item 1.2, entregamos para cada grupo, devidamente organizado em pontos estratégicos da sala de aula, oito fichas. Cada aluno deveria preenchê-las durante a leitura dos HQs de Maurício de Sousa, com a finalidade de sustentar a discussão dos mesmos no grupo (na comunidade de leitores) ${ }^{8}$. Assim, cada grupo distribuiu as funções entre seus componentes: 1- conector (liga o texto lido com a vida, com o momento); 2questionador (prepara perguntas, que analisam o texto, para os colegas); 3iluminador de passagens (escolhe uma passagem do texto para exemplificar ao grupo); 4- ilustrador (seleciona imagens interessantes do texto); 5-dicionarista (escolhe palavras consideradas difíceis ou relevantes para a leitura do texto); 6sintetizador (resume o texto), 7- pesquisador (busca informações contextuais que

\footnotetext{
${ }^{8}$ Segundo Cosson (2014), é um grupo de leitores que se reconhecem como parte de uma comunidade específica. O conceito empregado vem por empréstimo das leituras de Stanley Fish, Is there a text in this class? (1995) e de Roger Chartier, em A ordem dos livros: leitores, autores e bibliotecas na Europa entre os séculos XIV e XVIII (1999).
} 
são importantes para o texto) e 8- cenógrafo e perfilador (descreve as cenas principais e traça um perfil das personagens centrais).

Como os alunos estavam conhecendo tal procedimento de leitura literária, acompanhamos de perto a pré-discussão (preenchimento das fichas de leitura) em cada grupo, sanando as dúvidas, quando necessário. Concluída a etapa, cada grupo discutiu o seu texto com a comunidade de leitores, tendo como parâmetro as fichas preenchidas. Como nossos leitores-alvos não têm ainda maturidade leitora para manter um debate mais aprofundado sobre o texto, o material formalizado na pré-discussão foi, então, o centro da atividade ${ }^{9}$. Dessa maneira, compartilharam, em sala, suas leituras, "que não precisam ser negadas nem aceitas, mas expostas a todos (da comunidade de leitores)" (COSSON, 2014, p. 170), ou seja, tornaram latente o caráter social da interpretação de textos.

Após as discussões nos grupos a respeito do que foi lido, cada aluno registrou em cadernos, denominados "diários de leitura", suas reflexões sobre o texto. Num primeiro momento, os alunos foram dispostos em um círculo único para que lessem (de forma espontânea) seus registros dos diários. Em seguida, fizeram uma avaliação da atividade, na qual enfocaram o que funcionou bem e o que precisava ser melhorado para o círculo de leitura literária que seria iniciado com as obras selecionadas, que foram anteriormente citadas.

\subsubsection{Sistematização das atividades}

Montamos com os alunos um calendário das reuniões do círculo de leitura da literatura proposto. Como as obras em HQ são extensas (em média 150 páginas), fizemos oito momentos de duas horas/aulas (um mês) de discussão e registro de leituras na sala de aula. Dividimos as obras citadas acima em sete partes, pois a última reunião foi planejada para a leitura das historinhas poéticas de horror de José Paulo Paes. As funções que os participantes exerceram durante as reuniões foram as mesmas estabelecidas na modelagem, visto que já tinham sido orientados e suas possíveis dúvidas sanadas. No entanto, deixamos claro que, para o próximo círculo, as funções dos alunos seriam trocadas.

\footnotetext{
${ }^{9}$ Cosson (2014) orienta que, gradativamente, esse material deverá passar a ser apenas auxiliar da instauração e manutenção da discussão do texto ou obra no grupo.
} 
Feita a divisão, os alunos leram em casa as partes das obras estabelecidas na sala de aula e fizeram os registros nas fichas de funções. Nos dias marcados para a discussão dos grupos, foram utilizados vinte minutos para uma miniaula a respeito de algum aspecto relevante sobre a leitura ou sobre 0 funcionamento dos grupos. Na primeira aula, por exemplo, mostramos aos alunos as obras originais, das quais os HQs foram adaptados, falando brevemente, com o auxílio de data show, a respeito de cada uma, não deixando de focar o contexto sócio-histórico. A meia hora seguinte foi dedicada à discussão do que foi lido pelos alunos em casa, com base nas anotações que fizeram nas fichas de funções. Os vinte minutos posteriores foram reservados para o registro individual nos diários de leitura. Em seguida, fizemos um grande círculo e toda a turma comentou como estavam as leituras de seus grupos, em aproximadamente vinte minutos. Dos comentários, tiramos as atividades das miniaulas que foram ministradas em todos os encontros. Na sétima aula, a leitura e a discussão das obras em HQs foram encerradas e, assim, no momento em que fizemos o grande círculo, cada grupo apresentou oralmente o resumo da obra completa para toda a turma. Nessa aula, solicitamos que cada aluno viesse fantasiado, na próxima reunião, da personagem insólita tratada na obra que leu.

A última reunião, oitavo encontro, foi o encerramento do círculo de leitura literária proposto. Na miniaula, apresentamos o livro $E$ isso ali: poemas adultoinfanto-juvenis, de José Paulo Paes e falamos brevemente sobre o poeta, a temática, a forma e contexto sócio-histórico do poema "Quatro historinhas de horror". ${ }^{10}$ Em seguida, cada grupo recebeu o livro para efetuar a leitura das historinhas e foi solicitado que fizessem uma comparação entre a personagem do $\mathrm{HQ}$ e a personagem do poema. Depois, cada grupo leu a historinha poética que falava de sua personagem insólita para os outros grupos e expôs a comparação feita entre a personagem descrita no $H Q$ e a mesma descrita no poema. Para compor ainda mais o clima do horror na sala de aula, quando os grupos, com seus componentes devidamente fantasiados, estavam lendo as historinhas, as ilustrações do livro foram colocadas no data show, pois auxiliam a construir os sentidos do todo textual.

\footnotetext{
${ }^{10}$ Há nesse poema a presença da narratividade, que é determinante para a sua boa realização estética. Assim, as quatro historinhas que compõem o poema são narradas de forma independente e cada uma com começo, meio e fim.
} 


\subsubsection{Avaliação}

Como o objetivo do círculo de leitura literária foi contribuir para a construção de disponibilidade ao texto e do desejo de ler literatura dos alunos de uma turma de $5^{\circ}$ ano do Ensino Fundamental, fizemos uma observação dos registros efetuados por eles nos diários de leitura, durante as leituras dos HQs, para analisarmos em que medida tal procedimento surtiu efeito.

O que foi encontrado nos diários de leitura dos alunos? Manifestações sobre compreensão ou incompreensão acerca do lido; sínteses ou paráfrases; pedidos de esclarecimentos ou perguntas sobre acontecimentos dos textos, registros de palavras ou trechos bonitos, significativos ou de difícil compreensão; concordância ou discordância com determinada posição das personagens; acréscimos de argumentos favoráveis ou contrários à posição do interlocutor; emissão avaliativa - positiva ou negativa - sobre o que algumas personagens fizeram ou disseram ou sobre a forma como fizeram ou disseram alguma coisa; expressão de reações e emoções sobre a obra; relações do que foi dito na obra a alguma experiência pessoal; enfim, encontramos reflexões efetivas sobre as leituras realizadas. Nesse sentido, pode-se dizer que houve apropriação ${ }^{11}$ do que foi lido, ou seja, os alunos leitores estabeleceram relações entre o mundo em que vivem e o mundo dos textos, que ampliaram seus modos próprios de serem leitores e enriqueceram as suas identidades letradas e pessoais.

Machado et al (2004) postulam que o diário de leitura, diante de tantas possibilidades de registro, ajuda o leitor a ter uma atitude ativa, interativa e crítica sobre o texto ou obra literária lida, possibilita o desenvolvimento da escrita, do trabalho intelectual em geral e do desenvolvimento pessoal. É por isso, então, que o utilizamos como instrumento avaliativo para análises de questões relativas à formação dos leitores que participaram do círculo em questão.

É preciso ressaltar que os alunos já estavam familiarizados com a escrita do gênero, pois uma intervenção pedagógica havia sido feita, no início do corrente ano, com o objetivo de apresentá-la à turma

\footnotetext{
${ }^{11}$ Para Ricouer (1976), a apropriação se dá pelo estabelecimento de relações entre o mundo do leitor e o mundo do texto, o que amplia as descobertas literárias daquele e enriquece a sua identidade.
} 


\section{3 - Considerações finais}

Encerraremos o texto com uma citação de Cosson (2014, p. 176) que sintetiza, para nós, a eficácia dos círculos de leitura literária na escola. Para o autor, os círculos são práticas de letramento literário "[...] de grande impacto tanto para quem participa quanto para o espaço em que ele acontece." Para o aluno, salienta que o círculo é uma oportunidade de construção independente de aprendizagem (diálogo, resolução de problemas, liderança, argumentação, sintetização, exemplificação, registro, questionamento etc.) por meio da reflexão instaurada na comunidade de leitores. Além disso, a dinâmica, ainda segundo Cosson (2014), ajuda o aluno a desenvolver seu raciocínio, a apropriar-se da escrita e inserir-se no letramento literário, visto como um processo de apropriação de um sentido de literatura.

Não queremos dizer que, com todas as qualidades elencadas pelo pesquisador mencionado, o círculo de leitura literária seja a receita milagrosa para melhorar o ensino da leitura e da escrita na escola. O que acreditamos é que esse procedimento é uma das maneiras potenciais da instituição escolar contribuir para que a busca pelo sentido literário esteja pulsando, desde o ensino fundamental, na vida dos alunos.

\section{Referências bibliográficas}

COSSON, Rildo. Círculos de leitura e letramento literário. São Paulo: Contexto, 2014.

MACHADO, A. R.; ABREU-TARDELLI, L. S.; LOUSADA, E. Resenha. São Paulo: Parábola Editorial, 2004. Coleção Leitura e produção de textos técnicos e acadêmicos.

MACDONALD, F. Drácula. São Paulo: Companhia Editora Nacional, 2010.

Frankenstein. São Paulo: Companhia Editora Nacional, 2010.

2010.

O fantasma de Canterville. São Paulo: Companhia Editora Nacional,

PAES. José Paulo. Poesia para crianças: um depoimento. São Paulo: Editora Giordano, 1996. 
. É isso ali: poemas adulto-infanto-juvenis. São Paulo: Salamandra, 2005.

PETIT, Michèle. A arte de ler: como resistir à adversidade. Tradução de Arthur Bueno e Camila Boldrini. São Paulo: Editora 34, 2009.

RICOUER, Paul. Teoria da interpretação. Lisboa: Edições 70, 1976.

ROAS, D. A ameaça do fantástico: aproximações teóricas. Tradução Julián Fuks. São Paulo: Editora Unesp, 2014.

SHELLEY, M. Frankenstein. São Paulo: Editora L\&PM, 2009.

SOUSA, Maurício de. Sombras na parede. Cebolinha no. 10. São Paulo: Abril, 2008, p 52-60.

. Bons sonhos. Cascão no. 25. São Paulo: Abril, 2009, p 38-45.

2012, p 44-48.

O vampiro da sopinha de legumes. Mônica no. 68. São Paulo: Abril, . Uivo ulutante. Cascão no. 85. São Paulo: Abril, 2014, p 22-33.

STEVENSON, R, L. O Médico e o Monstro. São Paulo: Editora L\&PM, 2002.

STOKER, Brian. Drácula. São Paulo: Editora L\&PM, 2002.

WILDE, Oscar. O fantasma de Canterville. São Paulo: Editora L\&PM, 2002.

WILSON, S, M. O médico e o monstro. São Paulo: Editora Nacional, 2012. 
Artigo recebido em: 15 de dezembro de 2014

Artigo aprovado em: 25 de março de 2015

Sobre os autores:

João Carlos Biella é doutor em Estudos Literários pela Universidade Estadual Paulista Júlio de Mesquita Filho (2004). Professor adjunto do lleel-UFU (MG).

Sandra Borges é mestranda no Mestrado Profissional em Letras na Universidade Federal de Uberlândia. Tem experiência na área de Educação no Ensino Fundamental e Infantil. 